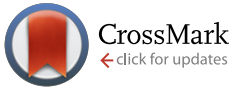

Cite this: Med. Chem. Commun., $2017,8,152$

\section{Synthesis and pharmacological evaluation of novel selective MOR agonist $6 \beta$-pyridinyl amidomorphines exhibiting long-lasting antinociception $\uparrow+$}

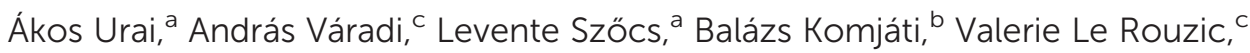 \\ Amanda Hunkele, ${ }^{C}$ Gavril W. Pasternak, ${ }^{c}$ Susruta Majumdar ${ }^{c}$ and Sándor Hosztafi*a
}

\begin{abstract}
It was previously reported that $6 \beta$-aminomorphinan derivatives show high affinity for opiate receptors. Novel $6 \beta$-heteroarylamidomorphinanes were designed based on the MOR selective antagonist NAP. The $6 \beta$-aminomorphinanes were prepared by stereoselective Mitsunobu reaction and subsequently acylated with nicotinic acid and isonicotinic acid chloride hydrochlorides. The receptor binding and efficacy were determined in vitro and the analgesic activity was studied in vivo. The in vitro studies revealed moderate selectivity for the MOR. At least two compounds in this series exhibited a long-lasting analgesic response when administered subcutaneously and intracerebroventricularly. When the substances were given intracerebroventricularly to mice, they showed analgesic potency comparable to morphine.
\end{abstract}

Received 3rd August 2016, Accepted 4th October 2016

DOI: $10.1039 / c 6 m d 00450 d$

www.rsc.org/medchemcomm opiate receptors, for example, a selective KOR agonist (nalfurafine), ${ }^{6}$ a selective MOR antagonist (clocinnamox), ${ }^{7}$ and a dual KOR/DOR agonist (MP1104). ${ }^{8}$ Several studies have been reported about $6 \beta$-aminomorphine derivatives developed in order to achieve higher selectivity to the MOR to mitigate the side effects of opiate analgetics. ${ }^{9,10}$

McDougall et al. prepared a series of $6 \beta$-morphine arylamides by the reaction of $6 \beta$-aminomorphine with aryl and heteroaryl acid chlorides. ${ }^{11}$ These derivatives were found to bind to the MOR with significant potency. Functional assays showed that the compounds were full MOR agonists. Li et al. carried out molecular modeling studies on the MOR and a new lipophilic binding domain was identified. ${ }^{12}$ Based on the modeling, a series of $6 \beta$-heteroaryl naltrexamine analogues were designed and synthesized with $6 \beta$ side chains including nicotinic, isonicotinic, and isoquinoline carboxylic acid amides. One of the most potent and selective to the MOR in the series was the nicotinic acid derivative, NAP (1), which was chosen as the lead molecule for further studies. ${ }^{12}$ The compound was found to be a potent peripheral MOR selective antagonist based on in vitro and in vivo pharmacological studies.

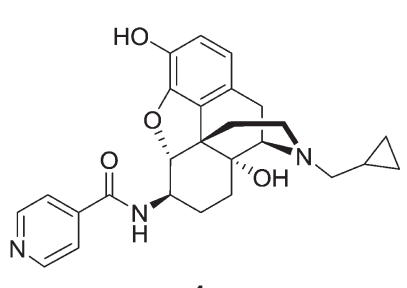

1

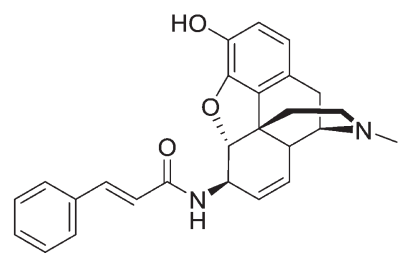

2
Fig. 1 Structures of $6 \beta$-amidomorphinanes. 

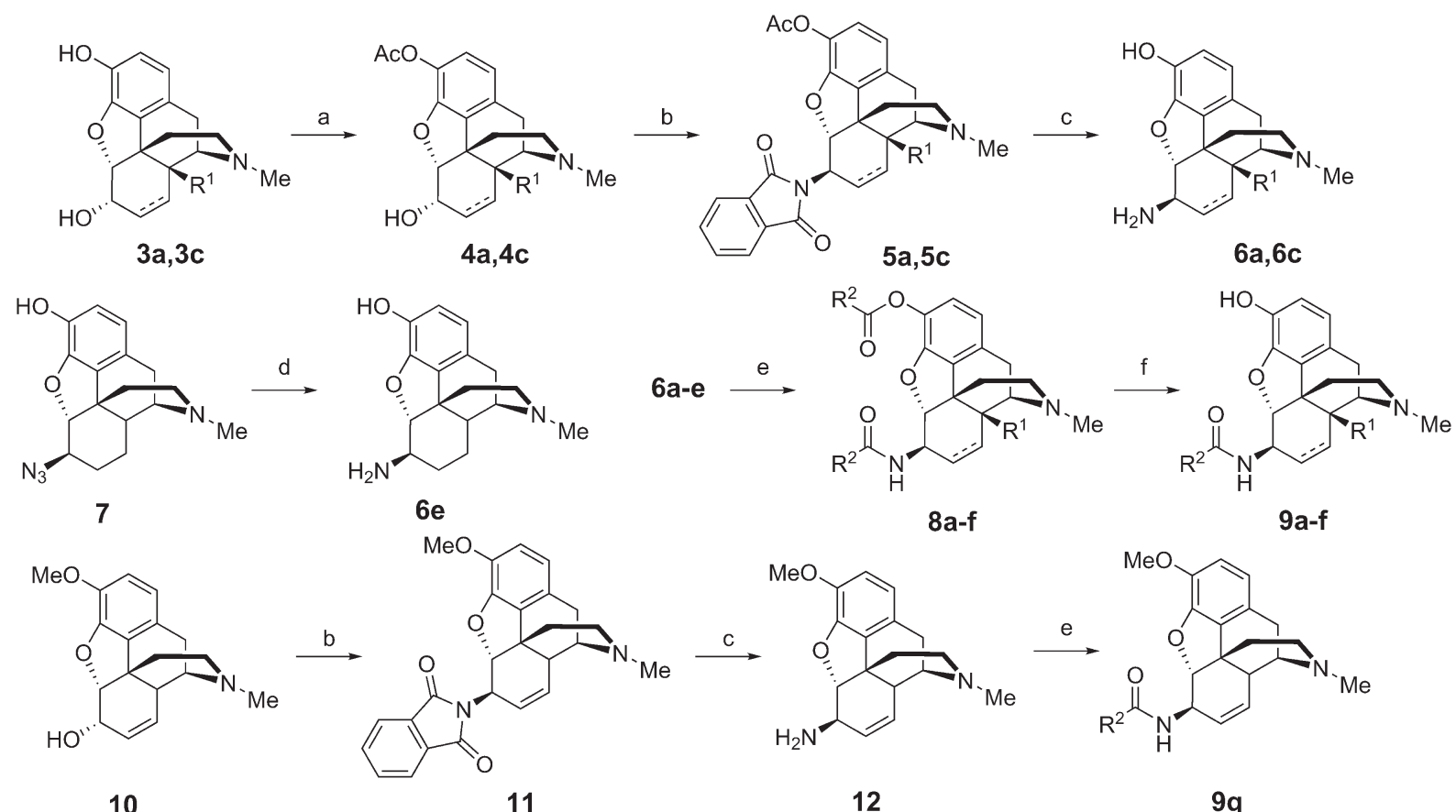

$6 e$

8a-f

9a-f
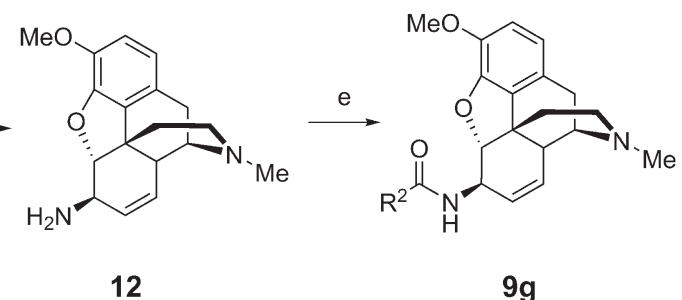

Fig. 2 Synthesis of $6 \beta$-amidomorphinans $9 a-g$. a) Acetic anhydride, $\mathrm{NaHCO}_{3}$ water r.t. 2 h; b) benzene/Ph $\mathrm{P}$, phthalimide, DIAD, r.t. 1 h; c) ethanol/hydrazine monohydrate, heating $3 \mathrm{~h}$; d) hydrazine monohydrate/RANEY® nickel, ethanol, r.t. 2 h; e) dichloromethane/acyl chloride, triethylamine; f) $\mathrm{K}_{2} \mathrm{CO}_{3} /$ methanol, heating $4 \mathrm{~h}$.

We have previously reported the synthesis of a series of novel 6 6 -cinnamoyl-morphinamines carrying various cinnamoyl side chains. ${ }^{13}$ In vitro and in vivo characterization of the synthesized compounds revealed high affinity for the MOR. The analgesic activity of $6 \beta$-cinnamoylmorphinamine (2) was found to be comparable to morphine, but with significantly reduced respiratory depression, a major side effect of commonly used opioids.

Here we report the design, synthesis, in vitro and in vivo evaluation of a series of selective MOR agonists, 6 6 -heteroarylamidomorphinanes, containing nicotinamide or isonicotinamide moieties at the $6 \beta$ position (Fig. 1).

\section{Results and discussion}

\section{Chemistry}

The 6 $\beta$-aminomorphinans $(6 \mathbf{6}, 6 \mathbf{c}, 12)$ were synthesized using the Mitsunobu reaction as described previously. ${ }^{13,14}$ Morphine (3c) and 14-hydroxy-dihydromorphine (3a) were selectively protected in the $\mathrm{C}-3$ position with acetic anhydride. ${ }^{15}$ Two acetyl protected derivatives $(\mathbf{4 a}, \mathbf{4 c})$ and codeine (10) were reacted in the Mitsunobu reaction with phthalimide and diisopropyl azodicarboxylate (DIAD) in the presence of triphenylphosphine to yield $6 \beta$-phthalimido morphinans (5a, $5 c, 11)$. The desired $6 \beta$-aminomorphinan derivatives (6a, $\mathbf{6 c}$, 12) were obtained upon treatment with hydrazine hydrate. The synthesis of $6 \beta$-aminodihydromorphine (6e) was accomplished from 6 6 -azidodihydromorphine (7). Bognár and Makleit reported the reduction of $6 \beta$-azidodihydromorphine (7) by lithium aluminum hydride in diethyl ether. ${ }^{16}$ We elab- orated an efficient new method for this reduction, utilizing hydrazine and RANEY ${ }^{\circledR}$ nickel in ethanol. ${ }^{17}$ With the new method, higher yields were achieved, work-up was easier and the final product did not require further purification (Fig. 2).

The $6 \beta$-aminomorphinans $(\mathbf{6 a - e})$ were reacted with nicotinic acid chloride and isonicotinic acid chloride in dry dichloromethane in the presence of triethylamine to yield the appropriate $6 \beta$-amidomorphinans. The acyl chlorides were synthesized as described in the literature. ${ }^{18}$ In the case of

Table 1 Structure of the studied compounds

\begin{tabular}{lllll}
\hline Compound & C7-C8 bond & $\mathrm{R}^{1}$ & $\mathrm{R}^{2}$ & $\mathrm{R}^{3}$ \\
\hline 9a & Single & $\mathrm{OH}$ & Isonicotinic & $\mathrm{H}$ \\
9b & Single & $\mathrm{OH}$ & Nicotinic & $\mathrm{H}$ \\
9c & Double & $\mathrm{H}$ & Isonicotinic & $\mathrm{H}$ \\
9d & Double & $\mathrm{H}$ & Nicotinic & $\mathrm{H}$ \\
9e & Single & $\mathrm{H}$ & Isonicotinic & $\mathrm{H}$ \\
9f & Single & $\mathrm{H}$ & Nicotinic & $\mathrm{H}$ \\
9g & Double & $\mathrm{H}$ & Isonicotinic & $\mathrm{Me}$
\end{tabular}

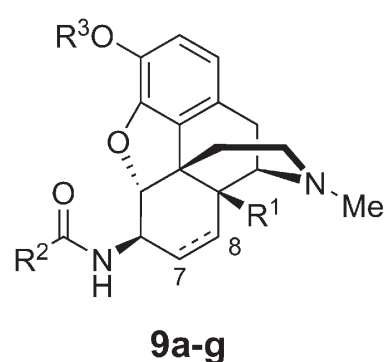

Fig. 3 General structure of the studied compounds. 
Table 2 Binding affinities of compounds $(9 \mathrm{a}-\mathrm{f})^{a}$

\begin{tabular}{|c|c|c|c|c|c|}
\hline \multirow[b]{2}{*}{ Compound } & MOR & KOR & DOR & \multirow[b]{2}{*}{$\mathbf{M} / \mathbf{K}$} & \multirow[b]{2}{*}{$\mathbf{M} / \mathbf{D}$} \\
\hline & $K_{\mathrm{i}}(\mathrm{nM})$ & & & & \\
\hline 9a & $7.02 \pm 0.77$ & $>100$ & $173.4 \pm 43.6$ & $>14.2$ & 24.7 \\
\hline $9 \mathrm{c}$ & $2.00 \pm 0.17$ & $77.9 \pm 31$ & $65 \pm 19.0$ & 39.0 & 32.5 \\
\hline 9d & $1.25 \pm 0.23$ & $18.97 \pm 5.3$ & $34.4 \pm 5.00$ & 15.2 & 27.5 \\
\hline $9 e$ & $3.73 \pm 0.14$ & $>100$ & $198.4 \pm 69$ & $>26.8$ & 53.2 \\
\hline $2^{c}$ & $0.10 \pm 0.02$ & $2.90 \pm 0.66$ & $10.26 \pm 6.76$ & 29.0 & 102.6 \\
\hline
\end{tabular}

${ }^{a}\left[{ }^{125} \mathrm{I}\right] \mathrm{BNtxA}(0.1 \mathrm{nM})$ competition binding assays were performed in membranes prepared from CHO cells expressing mouse MOR, DOR, or KOR, as previously described. Protein concentrations were between $10-20 \mu \mathrm{g} \mathrm{mL}^{-1}$ and the incubation time was 90 minutes. ${ }^{19} K_{\mathrm{i}}$ was determined by nonlinear regression analysis (GraphPad Prism). Assays were performed at least 3 times and means \pm SEM are reported.

${ }^{b}$ Values are taken from ref. $12 .{ }^{c}$ Values are taken from ref. 13.

Table 3 In vitro efficacy of the compounds in the $\left.{ }^{35} \mathrm{~S}\right] \mathrm{GTP} \gamma \mathrm{S}$ assay ${ }^{a}$

\begin{tabular}{|c|c|c|c|c|}
\hline \multirow[b]{2}{*}{ Compound } & \multicolumn{2}{|l|}{ MOR } & \multicolumn{2}{|l|}{ KOR } \\
\hline & $\mathrm{EC}_{50}(\mathrm{nM})$ & $\% E_{\max }$ & $\mathrm{EC}_{50}(\mathrm{nM})$ & $\% E_{\max }$ \\
\hline $9 \mathbf{a}$ & $26.42 \pm 3.17$ & $115.07 \pm 7.3$ & $\mathrm{nd}^{b}$ & $\mathrm{nd}^{b}$ \\
\hline $9 c$ & $4.62 \pm 0.28$ & $114.36 \pm 7.06$ & $\mathrm{nd}^{b}$ & $\mathrm{nd}^{b}$ \\
\hline 9d & $2.83 \pm 0.41$ & $113.63 \pm 4.54$ & $58.83 \pm 7.49$ & $87.88 \pm 4.9$ \\
\hline $9 e$ & $8.16 \pm 2.64$ & $114.85 \pm 1.26$ & $\mathrm{nd}^{b}$ & $\mathrm{nd}^{b}$ \\
\hline DAMGO & $19 \pm 7.0$ & $\mathrm{nd}^{b}$ & $\mathrm{nd}^{b}$ & $\mathrm{nd}^{b}$ \\
\hline U50,488H & $\mathrm{nd}^{b}$ & $\mathrm{nd}^{b}$ & $17 \pm 6.1$ & $\mathrm{nd}^{b}$ \\
\hline
\end{tabular}

molecules containing a free phenolic group (5a-e), the ester by-products were hydrolyzed with potassium carbonate in methanol.

\section{Binding studies}

The seven compounds used in in vitro and in vivo studies are summarized in Table 1. Codeine derivative $\mathbf{9 g}$ showed a significantly lower binding affinity compared with the morphine derivatives, suggesting that the free phenolic hydroxyl group is necessary for affinity at the receptor (Fig. 3).

Compounds 9a-f show similar nanomolar affinity for the MOR and much lower affinity for the DOR and KOR. In all cases, the difference in MOR affinities between the compounds possessing nicotinic acid and isonicotinic acid moieties was minimal; however, there are greater differences in affinities for the DOR and KOR. Compounds $9 a$ and $9 b$ having the 14-hydroxy dihydromorphine skeleton showed the lowest affinity to the MOR. The dihydromorphine derivatives $9 \mathrm{e}$ and 9f had the highest MOR/DOR selectivity among the studied molecules. The high MOR selectivity reported for the NAP, however, was not seen in this group. 9c and 9d had the

\section{Tail Flick Antinociception (icv)}

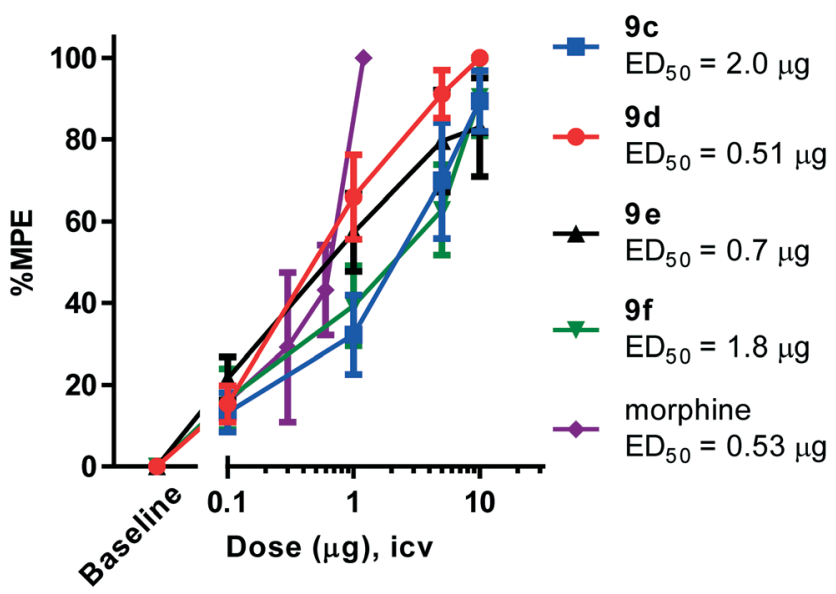

Fig. 4 Two independent determinations of the cumulative doseresponse curves were performed on groups of mice $(n=5)$ for antinociception in the tail flick assay with the compounds given intracerebroventricularly. The animals were tested $15 \mathrm{~min}$ later at the peak effect to generate the antinociceptive dose-response curve. Each point represents mean \pm SEM for 10 mice. $E_{50}$ values (and $95 \% \mathrm{Cl}$ ) were: 9c: $2.0 \mu \mathrm{g}(1.1,3.6)$; 9d: $0.51 \mu \mathrm{g}(0.3,0.9) ; 9 \mathrm{e}: 0.7 \mu \mathrm{g}(0.4,1.2) ; 9 f$ : $1.8 \mu \mathrm{g}(1.0,3.2)$; morphine: $0.53 \mu \mathrm{g}(0.27,1.0)$. 
highest affinity to the MOR. 9a only differs from NAP (1) in the substituent of the tertiary amine. The cyclopropylmethyl substituent of NAP (1) is responsible for the antagonistic effect; on the other hand, the methyl substituent in our compounds results in an agonistic effect. These results revealed that the saturation of the double bond and the presence of the $\mathrm{OH}$ group at 14-position are not beneficial in terms of binding (Table 2).

The $\left[{ }^{35} \mathrm{~S}\right] \mathrm{GTP} \gamma \mathrm{S}$-binding assay was used to characterize the functional activity of compounds $\mathbf{9 a}-\mathbf{f}$ in vitro on opioid transfected cell lines. In the $\left[{ }^{35} \mathrm{~S}\right] \mathrm{GTP} \gamma \mathrm{S}$ assay, all compounds were full agonists. 9c and 9d sharing the same morphine skeleton had the highest potencies. The $\mathrm{EC}_{50}$ value on the KOR was only determined for 9d, since no other analogs had considerable affinity for this receptor. It is well known in the literature that the saturation of the double bond and the presence of the 14-OH group increase the affinity of morphine derivatives. In our case, saturation of the double bond and the presence of the 14-OH group were not advantageous as these modifications decreased both the affinity and activity (Table 3). ${ }^{20,21}$

\section{In vivo studies}

All animal studies have been reviewed and approved by the IACUC. The animal care systems of the MSKCC are fully accredited by AAALAC and USDA are in compliance with the "Guide For the Care and Use of Laboratory Animals". We are also in compliance with the Animal Welfare Act and agree to adhere to the Public Health Service "Principles for the Use of Animals" (NIH Manual Chapter 4206). The antinociceptive activity of the four compounds (9c-f) with the highest affinity and agonism for the MOR was determined supraspinally in mice (Fig. 4) in a tail flick antinociception assay. While 9d was as potent as morphine $\left(\mathrm{ED}_{50}=0.53 \mu \mathrm{g}(0.27,1.0)\right)$ given icv, the other three compounds were $3-4 \times$ less potent antinociceptives. Upon subcutaneous administration, the compounds did exhibit an antinociceptive response at $30 \mathrm{mg} \mathrm{kg}^{-1}$
A) Tail Flick Antinociception at $30 \mathrm{mg} / \mathrm{kg}$

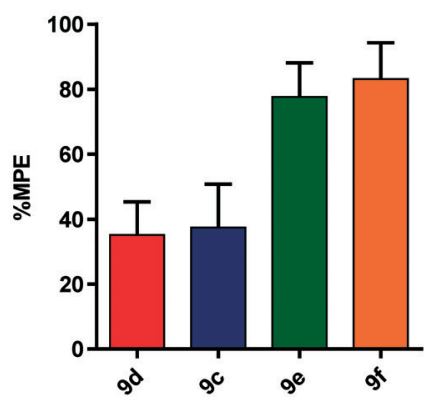

C) Time Course of Antinociception, icv

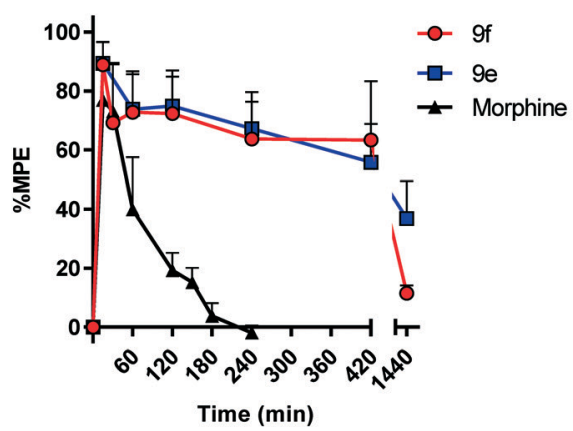

B) Time Course of Antinociception, sc

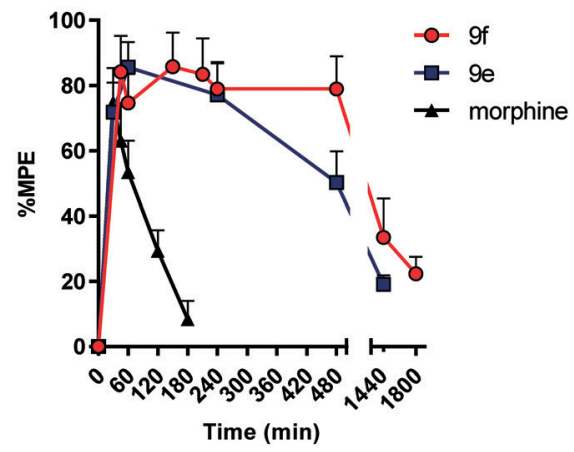

D) Reversal of Antinociception

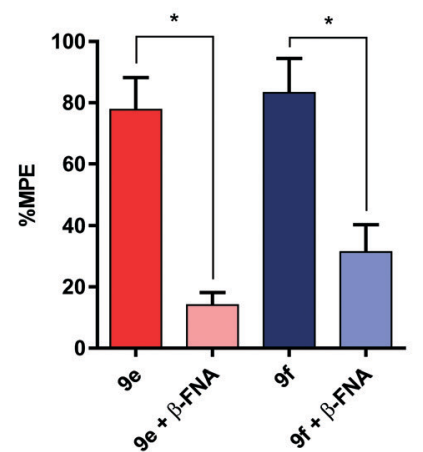

Fig. 5 A) Antinociceptive effect of compounds $9 \mathrm{c}-\mathrm{f}$. CD1 mice $(n=10)$ were given the compounds sc at $30 \mathrm{mg} \mathrm{kg}^{-1}$ and the antinociceptive effects were assessed 30 min post-injection using the radiant heat tail-flick method. Results (mean \pm SEM): $9 \mathrm{c}$ : $38 \% \pm 13 \%$; $9 \mathrm{~d}$ : $35 \% \pm 10 \%$; $9 \mathrm{e}$ : $78 \% \pm 11 \%$; 9 f: $83 \% \pm 11 \%$. B) Time course of the antinociceptive effect of morphine $\left(4.5 \mathrm{mg} \mathrm{kg}^{-1}\right)$, compound $9 \mathrm{e}(30 \mathrm{mg} \mathrm{kg})$, and $9 \mathrm{f}\left(30 \mathrm{mg} \mathrm{kg}{ }^{-1}\right)$ following sc administration to CD1 mice. Two independent determinations were performed on groups of mice $(n=10)$ for antinociception in the tail flick assay. C) Time course of the antinociceptive effect of morphine $(1 \mu \mathrm{g})$, compound $9 \mathrm{e}(7.5 \mu \mathrm{g})$, and $9 \mathrm{f}(7.5 \mu \mathrm{g})$ following icv administration to CD1 mice. Two independent determinations were performed on groups of mice $(n=10)$ for antinociception in the tail flick assay. D) Reversal of antinociception by selective antagonists. Groups of CD1 mice $(n=10)$ received $9 \mathrm{e}\left(30 \mathrm{mg} \mathrm{kg}^{-1}, \mathrm{sc}\right)$, or 9 f $\left(30 \mathrm{mg} \mathrm{kg}^{-1}\right)$ with or without $\beta$-funaltrexamine ( $\beta$-FNA; $40 \mathrm{mg} \mathrm{kg}^{-1}$, sc). $\beta$-FNA was administered 24 hours before agonist testing. All antinociception testing was performed 30 min after the administration of $9 \mathrm{e}$ and 9 . Similar results were observed in two independent replications. Antinociception was antagonized by $\beta$-FNA (two-way ANOVA followed by the Bonferroni post hoc comparison test, $p<0.05$ ). The means in each determination were determined as the percentage maximal possible effect (\%MPE) [(observed latency - baseline latency)/(maximal latency - baseline latency)] $\times 100$. The baseline latencies were between $2-3 \mathrm{~s}$ and the maximal latency was $10 \mathrm{~s}$ to avoid tissue damage. 
(solubility limitations didn't permit testing at higher doses). At this high dose, 9c and 9d exhibited about 30\% MPE, while 9e and 9f exhibited $\sim 80 \%$ MPE (Fig. 5A). The antinociceptive $\mathrm{ED}_{50}$ of morphine was $2.5 \mathrm{mg} \mathrm{kg} \mathrm{kg}^{-1}(1.8,3.4)$ in the same assay. We evaluated 9e and 9f further. Both compounds showed exceptionally long-lasting antinociception. In contrast to morphine's $3 \mathrm{~h}$ long antinociceptive response, the effect of 9e and 9 f lasted more than $24 \mathrm{~h}$ subcutaneously (Fig. 5B). Similarly, upon icv dosing, unusually long antinociception was observed, lasting more than $24 \mathrm{~h}$. This shows good correlation with the sc time course. Antinociception of both 9e and 9f was antagonized by $\beta$-FNA (Fig. 5D), a mu selective antagonist, confirming that the antinociception is mediated by $\mathrm{mu}$ opioid receptors.

Thus, these drugs do exhibit systemic antinociception, albeit at a higher dose. Their long-lasting antinociception makes these compounds exciting for further evaluation beyond thermal pain assays such as inflammatory and neuropathic pain models. The next set of analogs in this series will aim to optimize the potency of the compounds while maintaining long-lasting antinociception.

Several studies have been reported about NAP (1) as a selective peripheral MOR antagonist based on its in vitro/in vivo pharmacological assays and pharmacokinetic studies. ${ }^{12,22,23}$ To our knowledge, antinociceptive C-6 arylamido morphine with 3'-pyridyl or 4'-pyridyl as the aryl moiety has not been reported before. The pharmacology on C-6 amido morphinans has indeed been extensively studied but the SAR of novel compounds cannot be predicted based on that of known compounds. Subtle changes in the structure can have a huge impact on the in vivo pharmacology. It is well established that compounds with an $\mathrm{N}$-methyl substituent such as morphine and oxymorphone are agonists/antinociceptives. $N$-Allyl and $N$-cyclopropylmethyl ( $N$-CPM) lead to the antagonists naloxone and naltrexone, respectively. Some C-6 arylamido morphinans do follow this trend where the $N$-methyl leads to agonists/antinociceptives. ${ }^{11,13}$ Compounds with an $N$-CPM like NAP (ref. 12) from the Zhang group are antagonists and $\mathrm{N}$-CPM analogs ${ }^{24}$ are partial agonists. IBNtxA (ref. 25) and MP 1104 (ref. 8) are agonists/antinociceptives even with an $\mathrm{N}$-CPM moiety. The exceptionally long-lasting antinociception seen with 9e and 9f described in this paper has never been reported and is unexpected based on the published work on C-6 amido morphinans, suggesting the possibility of developing novel therapeutics with this template after further optimization of potency.

\section{Conclusions}

In summary, a series of 6-desoxymorphine-6 $\beta$-acylamides containing nicotinic or isonicotinic acid moieties were synthesized. The acyl side chains were chosen based on selective MOR antagonists reported in the literature. We found that the synthesized compounds are MOR full agonists with low affinity for the DOR and KOR. The compounds exhibited potent antinociception supraspinally and showed exceptionally long-lasting mu opioid receptor-mediated antinociception when given subcutaneously.

\section{Acknowledgements}

This work was supported by a research grant from the National Institute on Drug Abuse (DA034106) to SM. This research was funded, in part, through the NIH/NCI Cancer Center Support Grant P30 CA008748.

\section{References}

1 A. M. Trescot, S. Datta, M. Lee and H. Hansen, Pain Physician, 2008, 11, S133.

2 A. G. Hayes and M. Tyers, Br. J. Pharmacol., 1983, 79, 731.

3 G. D. Chiara and R. A. North, Trends Pharmacol. Sci., 1992, 13, 185.

4 H. H. Loh, H.-C. Liu, A. Cavalli, W. Yang, Y.-F. Chen and L.-N. Wei, Mol. Brain Res., 1998, 54, 321.

5 T. Caruso, A. Takemori, D. Larson and P. Portoghese, Science, 1979, 204, 316.

6 H. Kumagai, T. Ebata, K. Takamori, T. Muramatsu, H. Nakamoto and H. Suzuki, Nephrol., Dial., Transplant., 2010, 25, 1251.

7 S. D. Comer, T. F. Burke, J. W. Lewis and J. H. Woods, J. Pharmacol. Exp. Ther., 1992, 262, 1051.

8 A. Váradi, G. F. Marrone, S. O. Eans, M. L. Ganno, J. J. Subrath, V. Le Rouzic, A. Hunkele, G. W. Pasternak, J. P. McLaughlin and S. Majumdar, ACS Chem. Neurosci., 2015, 6, 1813.

9 T. P. Caruso, D. L. Larson, P. S. Portoghese and A. E. Takemori, J. Pharmacol. Exp. Ther., 1980, 213, 539.

10 S. J. Ward, D. LoPresti and D. W. James, J. Pharmacol. Exp. Ther., 1986, 238, 625.

11 J. M. MacDougall, X.-D. Zhang, W. E. Polgar, T. V. Khroyan, L. Toll and J. R. Cashman, Bioorg. Med. Chem., 2004, 12, 5983.

12 G. Li, L. C. Aschenbach, J. Chen, M. P. Cassidy, D. L. Stevens, B. H. Gabra, D. E. Selley, W. L. Dewey, R. B. Westkaemper and Y. Zhang, J. Med. Chem., 2009, 52, 1416.

13 A. Váradi, S. Hosztafi, V. Le Rouzic, G. Tóth, Á. Urai, B. Noszál, G. W. Pasternak, S. G. Grinnell and S. Majumdar, Eur. J. Med. Chem., 2013, 69, 786.

14 C. Simon, S. Hosztafi and S. Makleit, Synth. Commun., 1992, 22, 913.

15 L. H. Welsh, J. Org. Chem., 1954, 19, 1409.

16 R. Bognár and S. Makleit, Acta Chim. Acad. Sci. Hung., 1968, 58, 203.

17 A. A. Malik, S. B. Preston, T. G. Archibald, M. P. Cohen and K. Baum, Synthesis, 1989, 1989, 450.

18 J. Christensen, Molecules, 2001, 6, 47.

19 A. Váradi, T. C. Palmer, N. Haselton, D. Afonin, J. J. Subrath, V. Le Rouzic, A. Hunkele, G. W. Pasternak, G. F. Marrone, A. Borics and S. Majumdar, ACS Chem. Neurosci., 2015, 6, 1570.

20 A.-K. Gilbert, S. Hosztafi, L. Mahurter and G. W. Pasternak, Eur. J. Pharmacol., 2004, 492, 123.

21 A. F. Casy and R. T. Parfitt, Opioid Analgesics: Chemistry and Receptors, Springer, US, 2013. 
22 Y. Yuan, G. Li, H. He, D. L. Stevens, P. Kozak, K. L. Scoggins, P. Mitra, P. M. Gerk, D. E. Selley, W. L. Dewey and Y. Zhang, ACS Chem. Neurosci., 2011, 2, 346.

23 P. Mitra, J. Venitz, Y. Yuan, Y. Zhang and P. M. Gerk, Drug Metab. Dispos., 2011, 39, 1589.
24 S. Ghirmai, M. R. Azar, W. E. Polgar, I. Berzetei-Gurske and J. R. Cashman, J. Med. Chem., 2008, 51, 1913.

25 S. Majumdar, S. Grinnell, V. Le Rouzic, M. Burgman, L. Polikar, M. Ansonoff, J. Pintar, Y.-X. Pan and G. W. Pasternak, Proc. Natl. Acad. Sci. U. S. A., 2011, 108, 19778. 